\title{
INTESTINAL HELMINTHS OF THE WHITE STORK (CICONIA CICONIA LINNAEUS, 1758) FROM AN INTER-ROUTE SITE IN TURKEY
}

\author{
Ahmet Onur GIRISGIN ${ }^{1 *}$, Sezen BIRLIK ${ }^{2}$, Bayram SENLIK ${ }^{1}$ and \\ Hikmet Sami YILDIRIMHAN $^{2}$ \\ ${ }^{1}$ Department of Parasitology, Veterinary Faculty, Uludag University, Nilufer, \\ 16059 Bursa, Turkey; ${ }^{2}$ Department of Biology, Science Faculty, Uludag University, \\ Nilufer, Bursa, Turkey
}

(Received 24 October 2016; accepted 4 April 2017)

In Turkey, a study was conducted during the years 2009-2015 to detect the gastrointestinal helminth species of 18 white storks (Ciconia ciconia Linnaeus, 1758 (Aves: Ciconiiformes) sampled from aquatic or swamp areas of Bursa Province, one of the inter-route sites where storks intensely stay. The results of postmortem examination revealed that $17(94.44 \%)$ white storks harboured one or more helminth species. Eight species of helminths were detected at the following prevalence rates: Dictymetra discoidea (38.88\%), Chaunocephalus ferox (37.50\%), Schistocephalus solidus (27.77\%), Stephanoprora (Monilifer) spinulosa (18.75\%), Echinoparyphium sp. (12.50\%), Tylodelphys excavata (6.25\%), T. clavata (6.25\%), and Syncuaria ciconiae (6.25\%). This study is the first report on the presence of all the above species except T. excavata from white storks in Turkey. Stephanoprora (M.) spinulosa was found in Ciconiiform birds for the first time in this study.

Key words: Helminth, white stork, Ciconia ciconia, Turkey

Storks belong to the family Ciconiidae in the order of Ciconiiformes which comprises a number of families. In this family, there are 19 species of storks in six genera, many of which species are migratory. The white stork, $\mathrm{Ci}$ conia ciconia (Linnaeus, 1758), is a Palearctic migrant with a carnivorous opportunistic diet. This species is a long-distance migrant bird in most parts of Europe, northwest Africa and southwest Asia. This migratory bird winters in Africa from tropical Sub-Saharan Africa to as far as South Africa, or on the Indian subcontinent (Cox, 2010; Norton and Whiteside, 2014). Although there are no exact data about their number, it is thought that Turkey has the biggest reproducing population of white storks in Europe with 15,000 to 35,000 pairs. However, this number has tended to decrease in recent years.

\footnotetext{
*Corresponding author; E-mail: onurgirisgin@gmail.com
} 
Being a carnivore, the white stork eats a wide range of animal prey, including insects, fish, amphibians, reptiles, small mammals, snails, aquatic vertebrates, and small birds. It takes most of its food from the ground among low vegetation, and from shallow waters. Because of this feeding habitat, storks are exposed to numerous larval or adult parasites including helminths. The transmission of this infection may occur both in wintering and breeding sites. Comparative studies of parasite infections in native and alien host species are important to understand the role of parasites in biological invasions. Because of the high mobility of birds, it is often difficult to determine which parasites collected from them belong to the native fauna. Although there have been a few studies performed in other countries (Vicente et al., 1995; Parsani et al., 2003; Drago and Lunaschi, 2011), no systematic and detailed studies have been conducted on the white storks of Turkey to date.

The Bursa Province of Turkey $\left(40^{\circ} 10^{\prime} \mathrm{N} 28^{\circ} 37^{\prime} \mathrm{E}\right)$ is one of the breeding sites of white storks and contains four Important Bird Areas (Magnin et al., 2000).

Due to the lack of information about the helminths of storks, the objectives of this study were (i) to determine the species of helminths that parasitise white storks in Bursa Province, and (ii) to evaluate the prevalence, mean intensity and mean abundance of the helminth species recorded. In addition, this report represents the first systematically collected evidence on the diversity of helminth communities of storks.

\section{Materials and methods}

\section{Ethical standards}

The authors assert that all procedures contributing to this work comply with the ethical standards of the relevant national and institutional committees on human experimentation and with the Helsinki Declaration of 1975, as revised in 2008. The Ethics Committee approval (No. 2015 - 06/03) for applications and investigation (Date: 29 June 2015, No.: 138216) on birds has been obtained from the Uludag University Local Ethics Committee and the Ministry of Forestry and Water Affairs of Turkey, respectively.

\section{Study area}

Bursa Province is located in the southeast of the Marmara region (latitude: $40^{\circ} 11^{\prime}$, longitude: $29^{\circ} 04^{\prime} \mathrm{E}$ ), and is characterised by hot and dry summers with some rainfall. This region is also quite humid (average humidity: 69\%) due to its close proximity of the Marmara Sea. The mean annual temperature is between 14 and $16^{\circ} \mathrm{C}$, with minimum and maximum averages of $5{ }^{\circ} \mathrm{C}$ and $25^{\circ} \mathrm{C}$, respectively (Anonymous, 2014). 


\section{White storks}

The examined storks were found injured or dead by the local population of the aquatic or swamp areas of Bursa Province between August 2009 and December 2015. Altogether 18 injured birds were taken to the researchers after they had died despite all medical treatments and rescue attempts. Eight of the birds were necropsied immediately after death, while the others were kept frozen $\left(\right.$ at $\left.-18{ }^{\circ} \mathrm{C}\right)$ for a few days before necropsy.

\section{Necropsy}

During the postmortem examination, the body cavity of each bird was opened by a longitudinal incision, and the gastrointestinal tract was removed by cutting across the oesophagus and rectum. The oesophagus, stomach, small intestine and large intestine of each bird were examined separately for endoparasites. The contents of each organ were sieved through a $100-\mu \mathrm{m}$ aperture sieve, and the residue was transferred to Petri dishes and examined under a stereomicroscope. In addition, the mucosa of the gastrointestinal tract was examined under a stereomicroscope to determine if any small helminths were adhering to the mucosal layer. All of the helminths obtained from each organ were counted. Nematodes were inactivated in hot saline solution, fixed in $70 \%$ ethanol solution, mounted in glycerol, allowed to clear, and then examined. Cestodes and digeneans were fixed in $70 \%$ ethanol, regressively stained with haematoxylin, and mounted in balsam.

\section{Identification}

All helminths were identified under light microscope according to the figures and morphological features. Nematodes were identified according to the recommendations of Yorke and Maplestone (1926), Yamaguti (1961) and Anderson et al. (2009), trematodes according to the guidelines provided by Gibson et al. (2002) and Jones et al. (2005), while cestodes according to Skrjabin (1951), Schmidt (1986) and Khalil et al. (1994). Finally, representative helminth specimens were deposited in the helminth collection of the Museum of Zoology of Uludag University, Bursa, Turkey.

\section{Data analysis}

The terminology for describing infection parameters such as prevalence, mean intensity and mean abundance follows that of Bush et al. (1997). All of the calculations were performed using the Minitab (V-15) software package. 


\section{Results}

The 18 white storks necropsied included 7 males and 11 females. The overall prevalence of helminth infections was $94.44 \%$ (17 of 18 specimens) according to the necropsy results. The mean intensity, mean abundance, range and prevalence of each helminth species are presented in Table 1. As shown in Table 1, eight intestinal helminth ( 5 trematode, 2 cestode and 1 nematode) species were identified. No acanthocephalans were detected in the storks sampled. We collected a total of 291 helminths belonging to 8 species (Fig. 1).

The dominant species were Dictymetra discoidea (Beneden, 1868) (38.88\%) and Chaunocephalus ferox (Rudolphi, 1795) $(37.50 \%)$, found in the host's small intestine. The most prevalent species also had the highest intensities. There were no helminth-induced gross pathological changes in the intestines or in other digestive organs.

Meanwhile, all the helminths found in this study were adults, and no larval form or young individual could be detected. There was only one nematode species which was a female and had no eggs inside.

The helminth load reached 35 helminths per individual for $D$. discoidea, but only one helminth per individual for Tylodelphys excavata (Rudolphi, 1803) and Syncuaria ciconiae (Gilbert, 1927). While the number of available host specimens reached five in August, three in September, two in April and eight in May; the number of helminth individuals obtained in these months reached 51, 70, 32 and 135, respectively. The remaining helminth species were identified as T. clavata (von Nordman, 1832), Echinoparyphium sp., Stephanoprora (Monilifer) spinulosa (Rudolphi, 1809) Dietz 1909 and Schistocephalus solidus (Müller, 1776). All collected helminths were free in the intestinal lumen when they were detected by necropsy. All of the species except $T$. excavata were first and new geographical range extension records for Turkey.

Stephanoprora (M.) spinulosa is first recorded in Ciconiiform birds in this study. This species is $0.35 \pm 0.1 \mathrm{~mm}$ wide and $1.1 \pm 0.2 \mathrm{~mm}$ long, fairly elongate with a maximum width at the level of the ventral sucker. The tegument is armed with scale-like spines in alternating rows to the level of gonads posteriorly. The collar is well-developed with 22-26 collar spines. The oral sucker is spherical. The trematode occurs in the intestine of a wide range of fish-eating birds, mammals and reptiles. Cercariae lacking collar spines develop in Prosobranchia (sea, land and freshwater snails) and Pulmonate gastropods. Metacerceriae with collar spines occur on the gills or the inner surface of the oesophagus of freshwater fish (Gibson et al., 2002).

Variation in species richness, prevalence, mean intensity and mean abundance according to years is shown in Table 2. As it can be seen from that table, while the highest species richness was detected in the 2009-2010 study period, the lowest species richness was seen in 2015. 


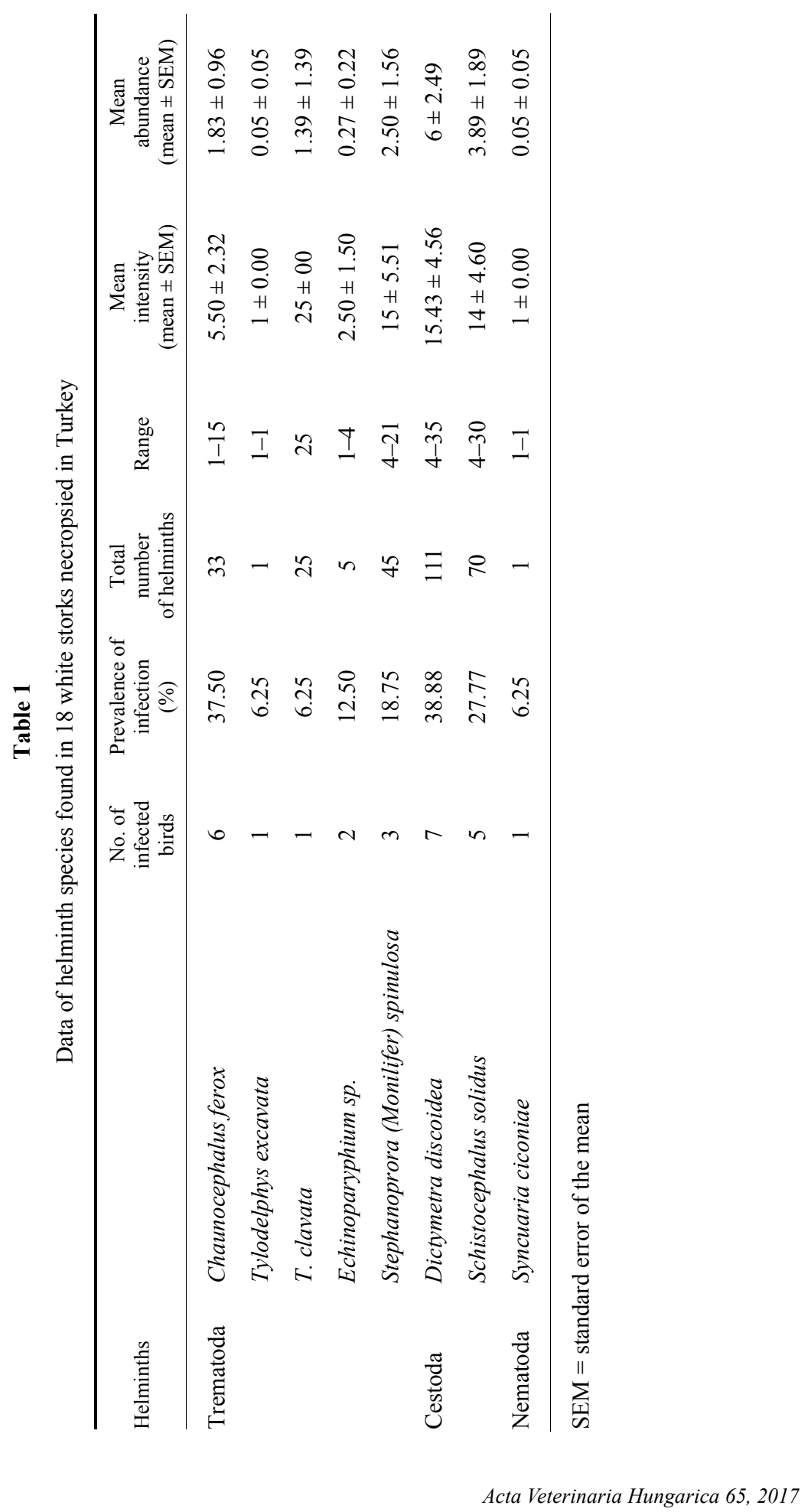


GIRISGIN et al.

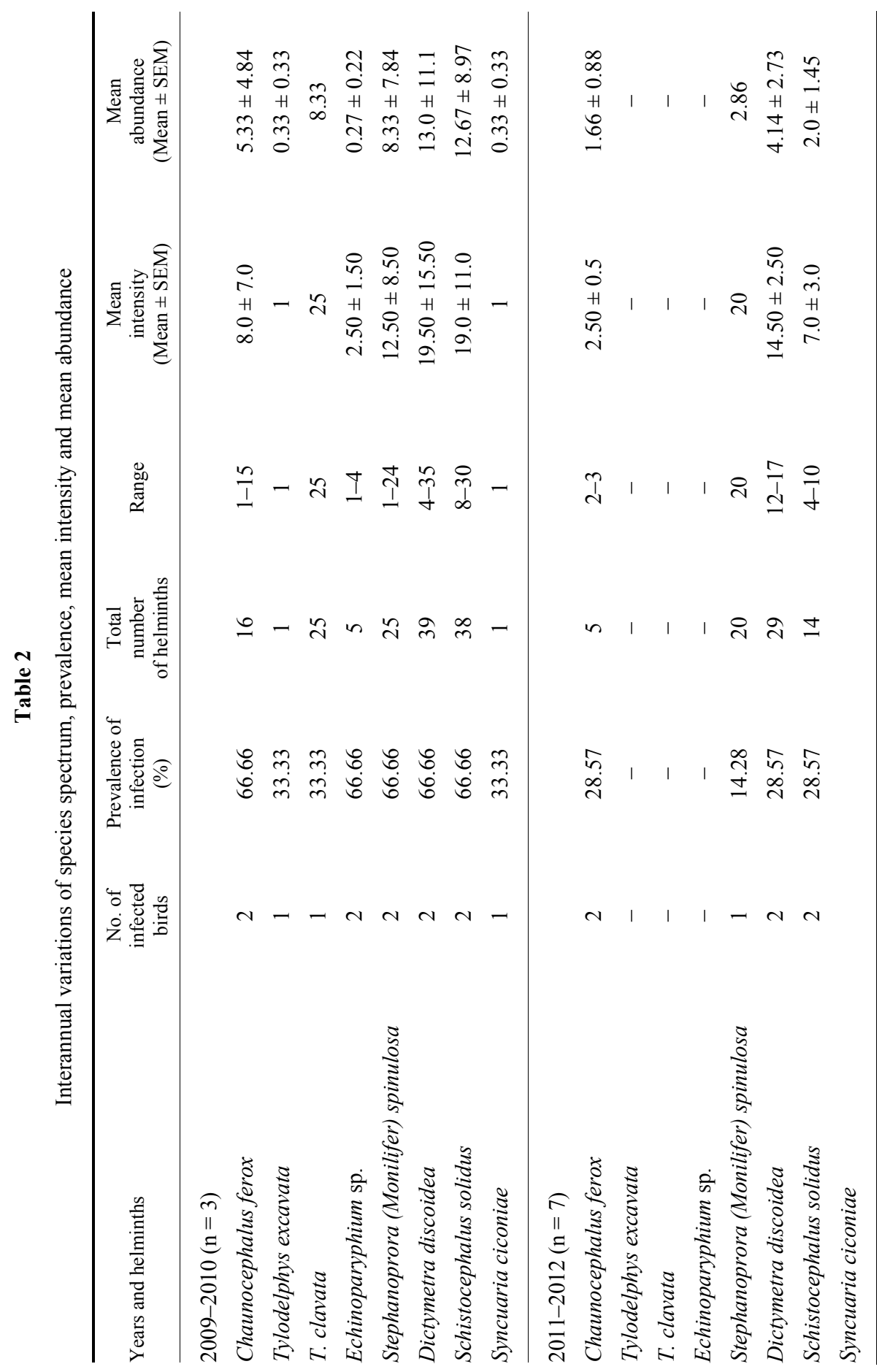

Acta Veterinaria Hungarica 65, 2017 


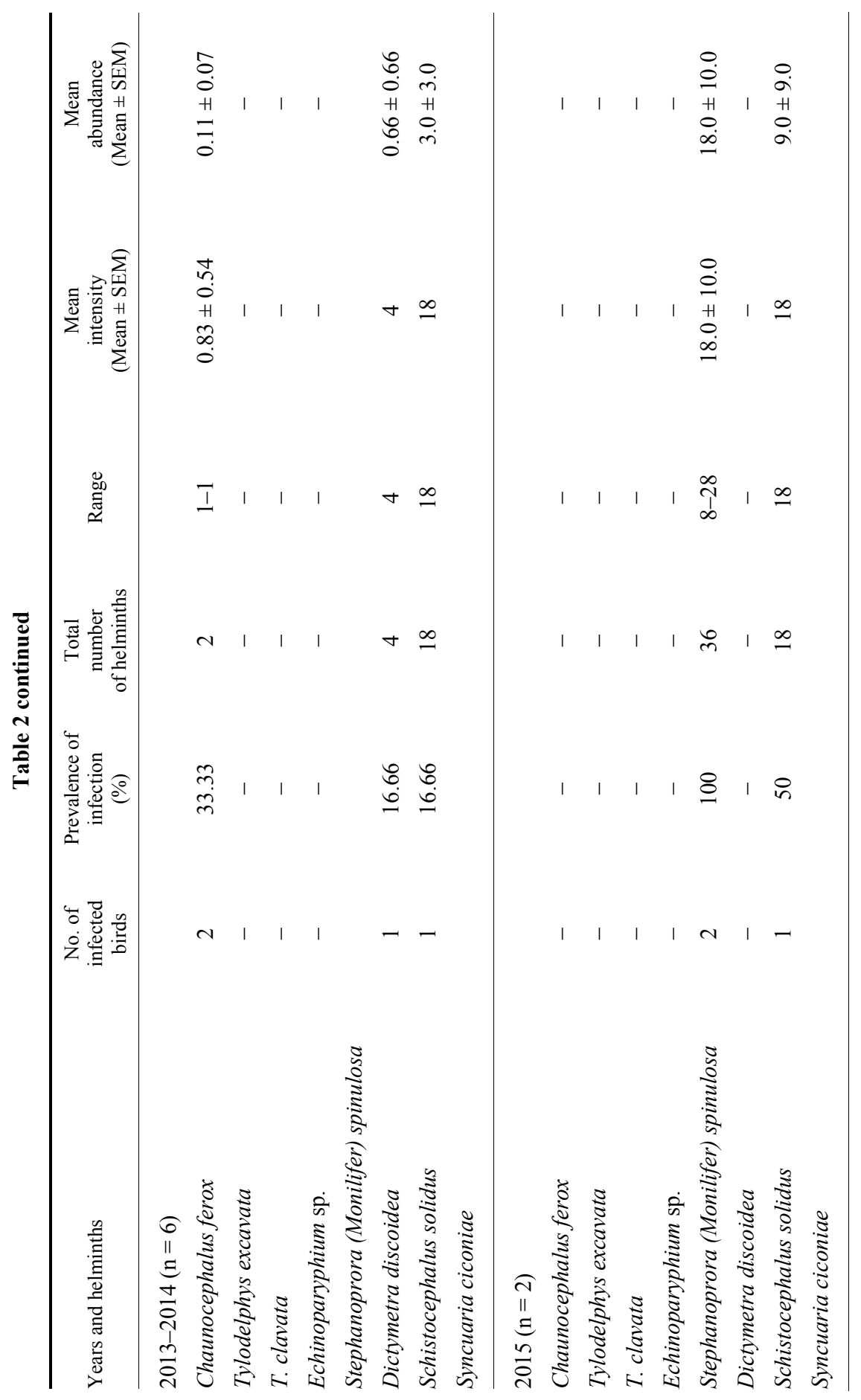




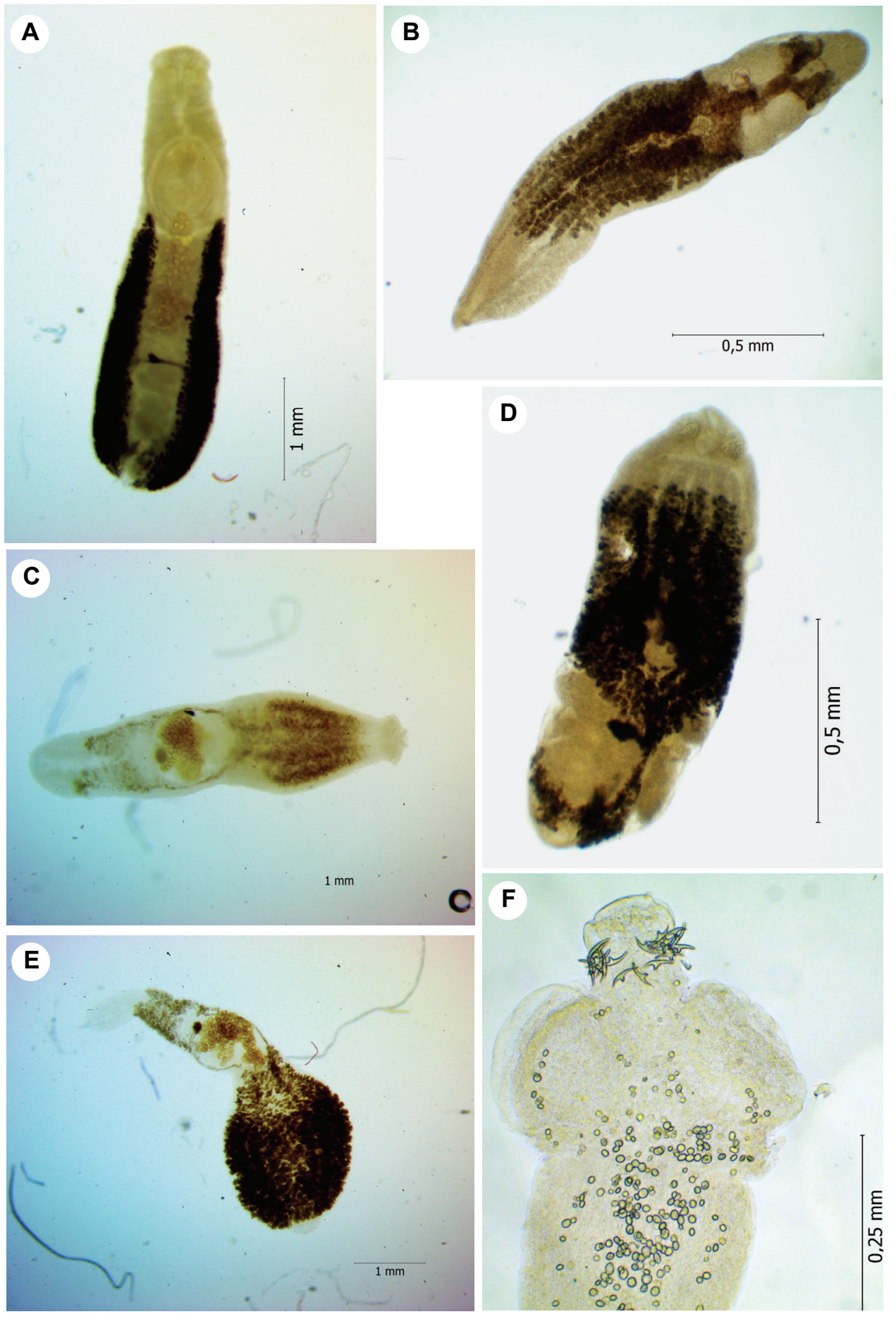

Acta Veterinaria Hungarica 65, 2017 


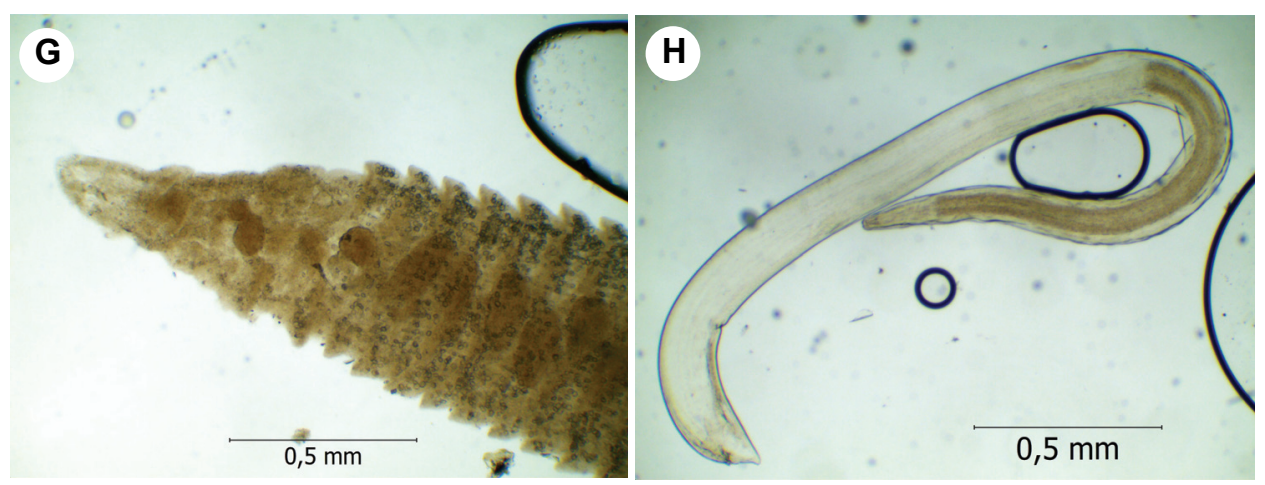

Fig. 1. Photos of helminths collected from white storks necropsied in Turkey. A: Echinoparyphium sp., B: Tylodelphys excavata, C: T. clavata, D: Stephanoprora (Monilifer) spinulosa, E: Chaunocephalus ferox, F: Dictymetra discoidea, G: Schistocephalus solidus, H: Syncuaria ciconiae

\section{Discussion}

Helminth infections in free-ranging birds can cause serious health problems when massive infections are combined with other factors or occur at times of stress. In addition to the direct effects induced by known pathogenic species, helminth infections may affect flight performance and predatory effectiveness, and they can also predispose to secondary trauma (Santoro et al., 2013). Therefore, the importance of bird health should not be overlooked. A thorough study of these parasites and the host-parasite relationships is needed for understanding their impact on the host.

Although there are nearly 483 bird species including three stork species in Turkey, there are only few studies addressing the composition of helminth communities of storks. This is due to the fact that white storks, like some other migratory birds, are under protection and, therefore, their hunting is prohibited throughout the year. Thus, there are only a few studies about the intestinal helminths of some wild birds in Turkey (Umur et al., 2010; Tezel et al., 2015).

Eight helminth species were recorded from white storks in this study. All of them except $T$. excavata are new records for the helminth fauna in Turkey. $T y$ lodelphys excavata had been detected from Ciconia ciconia in the Ankara Province of Turkey earlier (Coil and Kuntz, 1958). All the species found in our study had been previously described as parasitising white storks in various countries by different researchers (Vicente et al., 1995; Schuster et al., 2002; Parsani et al., 2003; Drago and Lunaschi, 2011), except $S$. (M.) spinulosa which was first recorded in Ciconiiform birds in this study. Storks may have become infected with the parasites when grazing on the swamp or ploughed fields in Turkey or in any other country where they migrate. 
Although three indigenous stork species (Ciconia ciconia, C. nigra and Mycteria ibis) exist in Turkey, only the white stork (C. ciconia) has been investigated for helminth infections in this study. A possible reason while we examined only this species is that it is more common than the others.

The prevalence of overall helminth infection was $94.44 \%$ in C. ciconia. Only one stork sample out of the 18 storks examined was not infected with helminths. Additionally, the prevalence rate varied from $6.25 \%$ to $38.88 \%$ depending on the species of helminths. Different helminth distributions have been detected from Ciconiid birds in various parts of the world by different researchers (Vicente et al., 1995; Arruda et al., 2001; Schuster et al., 2002; Drago and Lunaschi, 2011; Greben et al., 2016). Some of the helminth species found by some of these researchers correspond to our data (Arruda et al., 2001; Schuster et al., 2002; Greben et al., 2016). However, completely different species have been found in Ciconiform birds from Brazil and Argentina as compared to our study (Vicente et al., 1995; Drago and Lunaschi, 2011).

Some digeneans (trematodes), like Chaunocephalus ferox, can be more pathogenic to Ciconiiformes. They cause intestinal nodular lesions and traumatic lesions when penetrating the mucosa and submucosa (Patnaik et al., 1970; Santoro et al., 2013). The infection can cause debilitation and associated mortality in free-living populations of storks (Santoro et al., 2013). On the other hand, Sitko and Heneberg (2015) suggested that moderate infections of storks by helminths such as C. ferox and T. excavata were among the frequent causes of death in young storks by causing deep ulceration and severe catarrhal changes in the small intestine or weight restriction as shown in the case of C. ferox. However, in contrast to the findings of the above authors, no gross pathological lesions due to digeneans including $C$. ferox were observed in our study.

Dictymetra discoidea was the most prevalent (38.88\%) helminth species found in white storks in our study. However, other cestode species (Schistocephalus solidus) and the nematodes found in this study are considered nonpathogenic (Norton and Whiteside, 2014). Little is known about the pathological importance of these parasites. This may be explained by the fact that probably most of them have little pathogenic effect, due to the long-time parasite-host relationships. Another probable explanation is the lack of studies on the pathological effects of these parasites on storks (Barros, 2008). Nevertheless, this situation cannot change the fact that helminths can lead to serious health problems when massive infections are combined with other factors like being under stress. They may affect flight performance and predatory effectiveness, and can predispose the birds to secondary trauma (Santoro et al., 2013).

Free-ranging birds vary in the range and diversity of helminths that they harbour at any particular time. Due to the high mobility of storks, it is often difficult to determine which parasites collected from them belong to the native fauna. Examination of the intermediate hosts makes it possible to gain information 
about the sources of infection of definitive hosts. In our study, the intermediate hosts were not examined for the larval form of these parasites. So it is not possible to know exactly whether the infection originated from the local fauna or from abroad. However, the development characteristics of parasites obtained from storks in our study may indicate the foreign origin of these species. All species of helminths found in our study were adults, and no larval or young form could be detected. Therefore, we suggest that finding only adult helminths in storks indicates with a very high probability that these helminths are foreign parasites with which the storks became infected on the wintering grounds.

The interannual variation of species composition may arise from differences in the premigration and migration pathways used by their host species, the female reproductive cycle, or body fat changes during the winter and migration periods. On the other hand, changes in food composition, food quantity, physical activity of the birds and energy expenditure are all predicted to affect strongly the host's immune system and the species richness. In addition, differences in the helminth spectrum may also arise from different intermediate host species occurring on the migration pathway. Climatic changes from year to year and global warming markedly affect the life cycle of the intermediate hosts and the survival of the larval form. Hence, life cycles of the intermediate hosts and larval survival may strongly affect interannual changes in the parasite burden of storks. Thus, in the current study the highest abundance of species was detected in the 20092010 study period. Comparing the four study periods, the years 2009-2010 had a lower mean annual temperature than the other years. According to the National Centres for Environmental Information (NCEI) and the Turkish State Meteorological Service (TSMS), the highest global warming was seen from 2013 to 2015. In 2015 , the combined global land and ocean surface temperature was $0.9^{\circ} \mathrm{C}$ above the annual average of the 20th century. In our study, the species richness determined between 2013 and 2015 was very low in the storks examined. Therefore, we believe that this situation was caused by the effect of global warming on the parasites' intermediate host life cycle and larval survival.

In conclusion, our findings are compatible with those of other studies conducted on the helminths of Ciconiiform birds. As the diversity of helminth infections of Ciconiid birds has not been studied previously in Turkey, this study presents the intestinal helminth species of white storks for the first time. Stephanoprora (Monilifer) spinulosa represents a new record for Ciconiiform birds for the whole world. The impact of helminth infections on the well-being of storks should be investigated by a multidisciplinary approach in a more extensive study. 


\section{References}

Anderson, R. C., Chabaud, A. G. and Willmott, S. (2009): Keys to the Nematode Parasites of Vertebrates. Archival Volume. CABI Publishing, Oxfordshire. 480 pp.

Anonymous (2014): Turkish State Meteorological Service: Meteorological Data in Northwestern Turkey 1954-2013. Retrieved August 25, 2014 from http://www.dmi.gov.tr/veridegerlendirme/ il-ve-ilceler/istatistik.aspx?m=BURSA

Arruda, V. S., Pinto, R. M. and Muniz-Pereira, L. C. (2001): New host and geographical records for helminth parasites of Ardeidae (Aves, Ciconiiformes) in Brazil. Rev. Bras. Zool. 18 (Suppl. 1), 225-232.

Barros, L. A. (2008): Parasites and parasitic diseases of South American Ciconiiformes. In: Miller, R. E., Fowler, M. E. and Cubas, Z. S. (eds) Biology, Medicine and Surgery of South American Wild Animals. John Wiley and Sons, Hoboken, New Jersey, United Stares. pp. $87-92$.

Bush, A. O., Laferty, K. D., Lotz, J. M. and Shostak, A. W. (1997): Parasitology meets ecology on its own terms: Margolis et al. revisited. J. Parasitol. 83, 575-583.

Coil, W. H. and Kuntz, R. E. (1958): Records of trematodes collected in Turkey with the descriptions of new species in the families Lecithodendriidae and Plagiochiidae. Proc. Helminthol. Soc. Washington 25, 61-67.

Cox, G. W. (2010): Bird Migration and Global Change. Island Press, Washington. 291 pp.

Drago, F. B. and Lunaschi, L. I. (2011): Digenean parasites of Ciconiiform birds from Argentina. Rev. Mex. Biodivers. 82, 77-83.

Gibson, D., Jones, A. and Bray, R. (2002): Keys to the Trematoda. Volume 1. CAB International, London. $521 \mathrm{pp}$

Greben, O. B., Kudlai, O., Korol, E. N., Kornyushin, V. V., Vasilkovska, I. B. and Kobylinsky, V. V. (2016): A new record of Chaunocephalus ferox (Digenea, Echinostomatidae) from Ciconia nigra in Ukraine including morphological and molecular data. Vestn. Zool. 50, 99-104.

Jones, A., Bray, R. and Gibson, D. (2005): Keys to the Trematoda. Volume 2. CAB International, London. $745 \mathrm{pp}$.

Khalil, L. F., Jones, A. and Bray, R. A. (1994): Keys to the Cestode Parasites of Vertebrates. CAB International, Wallingford, Oxon. $768 \mathrm{pp}$.

Magnin, G., Eken, G. and Yarar, M. (2000): Turkey. In: Heath, M. F. and Evans, M. I. (eds) Important Bird Areas in Europe: Priority Sites for Conservation 2: Southern Europe. Birdlife International (Birdlife Conservation Series No. 8), Cambridge, U. K. pp. 651-655.

Minitab Inc. Statistical Software. Minitab Release, V-15 [computer software]. State College, PA, USA.

Norton, T. M. and Whiteside, D. P. (2014): Ciconiiformes (Herons, Ibises, Spoonbills, Storks). In: Miller, R. E. and Fowler, M. E. (eds) Fowler's Zoo and Animal Medicine. Volume 8. Elsevier Health Sciences, Oxford. pp. 100-101.

Parsani, H. R., Momin, R. R., Sahu, R. K. and Patel, B. G. (2003): Prevalence of gastro-intestinal parasites in captive birds at Kamla Nehru zoological garden, Kankaria Zoo, Ahmedabad. Gujarat. Zoos' Print J. 18, 987-992.

Patnaik, M. N., Rao, A. T., Acharjyo, L. N. and Mohanty, D. N. (1970): Notes on a nodular disease of the intestine of the open-billed stork (Anastomus oscitans) caused by Chaunocephalus ferox. J. Wildl. Dis. 6, 64-66.

Santoro, M., Degli Uberti, B., Galiero, G., Prisco, F., D’Alessio, N. and Veneziano, V. (2013): Chaunocephalus ferox (Digenea: Echinostomatidae) infection associated with fatal cachexia in a white stork (Ciconia ciconia). Helminthologia 50, 181-184.

Schmidt, G. D. (1986): Handbook of Tapeworm Identification. CRC Press, Boca Raton, Florida. $675 \mathrm{pp}$. 
Schuster, R., Schaffer, T. and Shimalov, V. (2002): The helminth fauna of indigenous White Storks (Ciconia ciconia). Berl. Münch. Tierarztl. Wochenschr. 115, 435-439.

Sitko, J. and Heneberg, P. (2015): Composition, structure and pattern of helminth assemblages associated with central European storks (Ciconiidae). Parasitol. Int. 64, 130-134.

Skrjabin, K. I. (1951): Essentials of Cestodology. Volume One. The Academy of Sciences of the USSR, Moscow.

Tezel, M., Girișgin, A. O., Birlik, S., Yıldırımhan, H. S. and Şenlik, B. (2015): Helminths of the digestive tract in Buteo buteo (Falconiformes: Falconidae) in Bursa Province of northwest Turkey. Turk. J. Zool. 39, 323-327.

Umur, Ş., Beyhan, Y. E., Pekmezci, G. Z., Açıc1, M. and Gürler, A. T. (2010): First record of Synhimantus (S.) laticeps (Rudolphi, 1819) Railliet, Henry et Sisoff, 1912 (Nematoda, Acuariidae) in Accipiter nisus (Aves, Accipitridae) in Turkey. Ankara Univ. Vet. Fak. Derg. 57, 139-142.

Vicente, J. J., Pinto, R. M., Noronha, D. and Gonçalves, L. (1995): Nematode parasites of Brazilian Ciconiiformes birds: a general survey with new records for the species. Mem. Inst. Oswaldo Cruz, Rio de Janeiro, 90, 389-393.

Yamaguti, S. (1961): Systema Helminthum. Volume III. The Nematodes of Vertebrates. Interscience Publishers Inc., New York. 679 pp.

Yorke, W. and Maplestone, P. A. (1926): The Nematode Parasites of Vertebrates. J. and A. Churchill, London, UK. 536 pp. 